\title{
Estudo SOBRE POSSÍveIS AVANÇOS NO PROCESSO DE APRENDIZAGEM DE ALUNOS COM BAIXA VISÃO UTILIZANDO MATERIAL DE ENSINO ADAPTADO PARA AULAS DE CIÊNCIAS
}

\author{
STUDY ABOUT POSSIBLE ADVANCES IN THE LEARNING PROCESS OF LOW \\ VISION STUDENTS USING TEACHING MATERIAL ADAPTED FOR SCIENCE \\ CLASSES
}

DOI: http://dx.doi.org/10.23926/RPD.2526-2149.2020.v5.n1.p306-324.id613

\section{Camila Maria \\ Gonçalves de Castro \\ Graduada em Ciências \\ Biológicas (UFVJM) \\ Se ligado a algum Programa \\ de Pós-Graduação, indicar. \\ camilinhacastro18@hotmail. \\ $\underline{\mathrm{com}}$}

\section{Giovana Evangelista \\ Alves \\ Graduada em Ciências \\ Biológicas (UNIFOR/MG) \\ gihalves25@gmail.com}

Cláudio Alves Pereira

Doutorando em Educação

(UFES)

claudio.pereira@ifmg.edu.br
Resumo: $\mathrm{O}$ artigo apresenta a discussão sobre materiais didáticos que auxiliam na educação inclusiva de alunos que possuem deficiência visual. As pesquisas têm apontado carência de recursos didáticos adaptados ao cotidiano escolar dos alunos com deficiência. O objetivo deste trabalho é apresentar um material didático adaptado que se mostrou eficiente e contribuiu para o avanço do processo de aprendizagem de uma aluna com baixa visão no estudo do conteúdo Sistema Digestório Humano. A pesquisa é do tipo estudo de caso e o seu paradigma é do tipo qualitativo. O desenho metodológico incluiu a organização de duas entrevistas semiestruturadas com uma aluna com baixa visão, sendo uma anterior e outra posterior à prática com o uso do material adaptado. Com o presente estudo, foi possível concluir que a utilização de recursos didáticos demonstra potencial positivo na promoção da aprendizagem significativa de alunos com deficiência visual na disciplina de Ciências.

Palavras-chave: Educação Inclusiva; Recursos Didáticos; Ciências.

\begin{abstract}
This article presents the discussion about the didatic materials that help in inclusive education for students with visual impairment. Research has pointed to a lack of didactic resources adapted to the daily school life of students with disabilities. The objective of this paper is to present an adapted didatic material that proved to be efficient and contributed to the advancement of the learning process of a student with low vision in the study of the Human Digestive System content. The research is of the case study type and its paradigm is of the qualitative type. The methodological design included the organization of two semi-structured interviews with a student with low vision, one before and one after the practice with the use of adapted material. With the present study, it was possible to conclude that the use of didactic resources demonstrates positive potential in promoting the meaningful learning of visually impaired students in the Science discipline.
\end{abstract}

Keywords: Inclusive Education; Didactic Resources; Sciences. 


\section{INTRODUÇÃ̃O}

A Declaração Universal dos Direitos Humanos (ONU, 1948) garante aos indivíduos condições que lhes permitam viver com dignidade. De igual maneira, a Constituição Federal Brasileira (BRASIL, 1988) assume o compromisso proposto pela Organização das Nações Unidades (ONU), garantindo os princípios de igualdade e o direito a uma educação de qualidade, enfatizando importantes medidas constitucionais em favor das pessoas com deficiência. A constituição brasileira estabelece que o direito à educação deve ser de todos os cidadãos, além de igualdade e condições de acesso e permanência à escola, sendo dever do Estado garantir o atendimento educacional especializado, preferencialmente na rede regular de ensino.

O Estatuto da Criança e do Adolescente (BRASIL, 1990), instituído pela Lei n 8.069, determina o direito da criança à educação, em igualdade de condições para acesso à escola e seu desenvolvimento na sociedade, disponibilizando atendimento educacional especializado. A Lei de Diretrizes e Bases da Educação Nacional (LDB), no 9.394 (BRASIL, 1996), estabelece os fundamentos da educação brasileira e reconhece a importância da Educação Especial. Ela institui, dentre outras obrigatoriedades, o direito de o estudante com deficiência frequentar o ensino regular, bem como o direito à organização curricular e recursos educacionais adequados para cada aluno.

Dessa forma, havendo a justificativa da pesquisa apresentada em base legal, o ambiente do estudo escolhido foi uma escola estadual da cidade de Arcos/MG, que possui atendimento educacional especializado (AEE) a alunos com necessidades especiais (NE). A turma escolhida foi um oitavo ano, por possuir, em sua composição, uma aluna com baixa visão - sendo esta o sujeito de análise para o estudo. Outro motivo para a escolha dessa turma de oitavo ano foi devido ao fato de ela apresentar, no planejamento anual de aulas, o estudo sobre o sistema digestório, que além de ser interessante e importante para o dia a dia do aluno, apresenta facilidade para que o professor possa criar recursos didáticos, sendo então o tema escolhido para ministrar a aula e confeccionar o material adaptado.

Portanto, o objetivo do presente estudo foi desenvolver uma prática educativa com o uso de material didático adaptado para alunos com baixa visão. Foram estabelecidas as seguintes etapas para o desenvolvimento do estudo: a) conhecer o entendimento das práticas cotidianas de estudo na perspectiva da aluna com baixa visão em relação ao ensino de Ciências, por meio de uma entrevista semiestruturada; b) definir o tema a ser trabalhado no presente 
estudo e preparar o material adaptado para a prática em sala de aula; e c) realizar uma segunda entrevista com a aluna com baixa visão, após a prática em sala de aula.

Propõe-se demonstrar as possibilidades do uso de materiais didáticos adaptados e, com isso, incentivar outros docentes a investirem nessa metodologia de ensino, visto que os materiais utilizados na confecção dos modelos e maquetes são de baixo custo e promovem a participação coletiva dos alunos, a oportunidade para trabalhar outros valores pessoais na própria dinâmica da atividade, como o respeito às diversidades, trabalho em equipe, divisão de tarefas, cumprimento de prazos, valores sociais, dentre outros.

\section{REFERENCIAL TEÓRICO}

Segundo Allves (2017), um ensino de qualidade deve levar em consideração as particularidades do aluno, e o professor deve ser capacitado para difundir o seu conhecimento e oferecer aos estudantes oportunidades de aprender, sejam eles deficientes ou não.

De acordo com Laguna (2012), a inclusão deve atender a integração dos alunos na escola, a eliminação da assistência individualizada, a criação de diferentes técnicas de ensino e novas organizações na estrutura da escola do aluno com deficiência.

A educação inclusiva deve ser fundamentada em linguagens e construção de métodos efetivos para todos os alunos e em teorias de elaboração de meios didáticos que sejam aplicados pelos professores para ajudá-los em suas aulas. O sistema educacional deve então apresentar uma educação de qualidade e diversificada que corresponda aos alunos, para que possa garantir a eficiência da inclusão (ANDRADE; IACHEL, 2017).

\subsection{A ESCOLHA DO ALUNO COM BAIXA VISÃo}

No Brasil, a inclusão escolar é direito de todos os estudantes que manifestam qualquer tipo de deficiência, levando em conta as suas competências intelectuais. A pessoa deficiente com baixa visão apresenta um resíduo de visão considerável para ver luz e tomar direção a partir dela. Sua metodologia educativa ocorre por meio visual, utilizando técnicas específicas. O deficiente visual, em geral, possui seu intelectual resguardado viabilizando ao docente produzir uma diversidade de práticas de ensino para que a inclusão seja efetiva em sala de aula (LAGUNA, 2012).

O ensino de Ciências para alunos com deficiência visual e aos videntes é constituído por linguagens e criação de metodologias eficientes e tem como objetivo a construção do estudante como cidadão, desenvolvendo capacidades sobre ciência, tecnologia e sociedade, associando o 
senso crítico sobre o espaço e o tempo, melhorando o raciocínio lógico sobre o mundo (ANDRADE; IACHEL, 2017).

Segundo Laguna (2012), a escola e a sociedade devem estabelecer condições para que o aluno deficiente visual seja inserido no ensino regular, oferecendo uma educação de qualidade. Os requisitos básicos para que a educação inclusiva consiga estimular as competências do aluno, são: a orientação da aprendizagem, o auxílio às necessidades do estudante e a adequação curricular. Sendo assim, em uma educação inclusiva para o aluno deficiente visual, são necessárias adequações de métodos didáticos com a finalidade de concretizar conceitos. Dessa forma, o incentivo visual é importante, pois estimula o estudante a usar de forma adequada sua visão residual com recursos ópticos (uso de lentes ou lupas), caso necessite, a fim de melhorar sua aprendizagem.

Os estudantes deficientes visuais necessitam de metodologias que os ajudem a construir seus conceitos, além de docentes que estimulem o seu interesse. Assim, deve-se assumir que os recursos pedagógicos são essenciais e desenvolvem a aprendizagem, possibilitando a autonomia no desenvolvimento intelectual do aluno (LAGUNA, 2012).

Cardinali (2008) afirma que o ensino inclusivo nas escolas é um importante processo para a compatibilidade de oportunidades de aprendizado e que existe uma grande carência de materiais de ciências destinados ao estudante deficiente visual, constituindo a ideia de que essa disciplina seja excludente quando não há modelos anatômicos tridimensionais.

\subsection{CARÊNCIA E IMPORTÂNCIA DE METOdologias/RECURSOS DIDÁticos QUE AUXILIEM ALUNOS COM DEFICIÊNCIA VISUAL}

O desenvolvimento de recursos e metodologias didáticas no processo de aprendizagem do aluno deficiente visual é importante, pois possibilita que o mesmo compartilhe as tarefas com os demais alunos e aprenda de modo parecido com os estudantes que não possuem deficiência visual, visto que seu intelectual geralmente está preservado e os recursos oferecem oportunidades para alcançar os objetivos. O estudante com deficiência visual deve ser incentivado a usar metodologias didáticas que auxiliem o enriquecimento de sua aprendizagem para desenvolver a percepção tátil. Assim, o progresso desses alunos e suas particularidades são fundamentais para a elaboração de técnicas educacionais (LAGUNA, 2012).

Como versado anteriormente por Cardinali (2008), o ensino de ciências pode ser visto como uma matéria excludente para os alunos com deficiência visual quando há carência de recursos táteis. Essa ausência dos recursos didáticos pode ser verificada devido às informações 
reduzidas nos livros-textos e no tratamento de ilustrações bidimensionais (LONGHI; SCHIMIN, 2008).

Portanto, o docente deve criar metodologias educacionais que estimulem a curiosidade e uma aprendizagem significativa aos alunos. Dentre tais metodologias, destaca-se o uso de maquetes (SOUZA; FARIA, 2011).

A confecção de materiais didáticos deve levar em consideração alguns fatores como o custo, o acesso aos objetos necessários e a experiência do professor para a confecção dos mesmos. São sugeridos então materiais que são fáceis de serem encontrados, como o MDF, EVA, gesso, isopor, papelão, barbante, alfinete. A construção de materiais didáticos inclusivos é importante na melhoria de um ensino abrangente em salas de aula. Assim, entende-se que os materiais aqui apresentados como exemplos possam contribuir para que os professores iniciem sua didática voltada para a inclusão (ANDRADE; IACHEL, 2017).

Para que o aluno faça parte de uma educação inclusiva eficaz, é importante que ela seja significativa e desperte a vontade de aprender. Os materiais didáticos são essenciais para estimular a efetivação dos conceitos, produzir um ensino eficiente, possibilitar a criação de aprendizados e o entendimento de informações e experiências relevantes na percepção da sociedade como um todo (LAGUNA, 2012).

\subsection{A IMPORTÂNCIA DO TEMA ESCOLHIDO: O SISTEMA DIGESTÓRIO}

O sistema digestório é um tema interessante e muito importante no processo de aprendizagem do aluno, uma vez que é um conteúdo presente no dia a dia do indivíduo e que possui certa facilidade para o professor criar recursos didáticos, como, por exemplo, a confecção de maquetes e materiais com formato dos órgãos digestivos, desenvolvendo então competências diferenciadas aos estudantes.

\section{Procedimentos metodológicos}

O lócus escolhido para a pesquisa foi a Escola Estadual da Vila Boa Vista, em Arcos/MG, uma vez que a escola possui atendimento educacional especializado (AEE), alunos com necessidades especiais (NE) e pelo fato de uma das professoras-pesquisadoras já ter trabalhado na escola citada e na turma de oitavo ano escolhida para o estudo.

A classe foi identificada como tendo potencial para a pesquisa por ter uma aluna com baixa visão, que é o sujeito de análise do estudo, e por apresentar também essa proximidade cotidiana, na qual uma das professoras-pesquisadoras já conhecia a realidade e a necessidade de aulas com recursos didáticos apropriados para um melhor processo de ensino-aprendizagem 
da turma, em geral, e para a aluna com baixa visão, em especial. A aluna citada apresenta deficiência visual parcial e possui capacidade intelectual preservada.

A pesquisa foi estruturada como um estudo de caso e os pesquisadores optaram pela abordagem qualitativa dos dados. Segundo Yin (2001, p. 19), “os estudos de caso representam a estratégia preferida quando se colocam questões do tipo 'como' e 'por que', quando o pesquisador tem pouco controle sobre os eventos e quando o foco se encontra em fenômenos contemporâneos inseridos em algum contexto da vida real”.

Esclarecendo sobre o paradigma qualitativo para a análise dos dados desta pesquisa, Gerhardt e Silveira (2009, p.31) apontam que a "pesquisa qualitativa preocupa-se [...] com aspectos da realidade que não podem ser quantificados, centrando-se na compreensão e explicação da dinâmica das relações sociais". Ainda segundo os autores, "a pesquisa qualitativa não se preocupa com representatividade numérica, mas, sim, com o aprofundamento da compreensão de um grupo social, de uma organização etc" (p. 32).

Primeiramente, foi realizada uma pesquisa na literatura científica com o objetivo de selecionar projetos que levassem em consideração a inclusão de deficientes visuais nas práticas escolares. Assim, as professoras-pesquisadoras identificaram potencial no estudo do sistema digestório com o uso de material adaptado. Após ter sido definida a temática, foram pesquisados os referenciais teóricos nas plataformas Scielo e Google Acadêmico.

Como ferramenta para a coleta de dados e confecção do material didático, as professoras-pesquisadoras elaboraram uma entrevista semiestruturada que foi aplicada em particular à aluna com deficiência visual, cujas perguntas e respostas dessa entrevista constam no Anexo $I$.

A entrevista foi realizada no dia 13/03/2019 e teve como objetivo avaliar as dificuldades encontradas pela aluna com baixa visão no decorrer das aulas ministradas pela professora responsável pelas aulas de ciências dessa turma, levando em consideração as metodologias de ensino utilizadas por esta professora. Foram planejadas quatro perguntas, sendo elas: "A forma como as aulas de Ciências é organizada pela professora tem contribuído para o seu aprendizado? Conte-nos como normalmente são organizadas as suas aulas de Ciências", "Conte-nos sobre uma aula de Ciências que lhe marcou pela forma como o conteúdo foi trabalhado", "Em qual disciplina você sente mais motivada a estudar? Por quê??" e "Fale sobre o que poderia ser melhorado nas aulas de Ciências para facilitar a sua aprendizagem". As respostas dadas pela aluna foram determinantes para o planejamento da atividade e podem ser conferidas no Anexo $I$. 
A partir da análise das respostas da aluna com baixa visão e dos dados coletados no referencial teórico selecionado, foi confeccionado pelas professoras-pesquisadoras no dia 10/04/2019 uma maquete similar ao sistema digestório humano (Figuras 1 e 2). Como base para confecção dessa maquete, foi utilizado um isopor para esboço com caneta hidrocor nas cores azul, vermelha e preta, de um corpo humano da cabeça até a região abdominal, em tamanho aproximado ao real de um adulto. Os órgãos e as glândulas anexas do sistema digestório humano foram confeccionados em material de Etil Vinil Acetato (E.V.A).

Utilizando como molde imagens dos órgãos do sistema digestório humano retiradas da internet, cada órgão desse sistema foi recortado no material de E.V.A. em cores específicas: glândulas salivares (lilás), faringe (azul), esôfago (roxo), fígado (verde), estômago (vermelho), vesícula biliar (rosa claro), pâncreas (laranja), intestino delgado (marrom), intestino grosso (amarelo) e ânus (azul). De maneira a permitir o manuseio desses órgãos e aumentar as possibilidades de interação dos alunos com o material concreto, as peças (órgãos) foram planejados para que pudessem ser destacados do isopor, ação que permitiu aos alunos o uso de outro sentido adicional à visão: o tato.

Todos os órgãos possuíam cores fortes, algumas brilhantes e textura áspera, estratégia traçada para auxiliar no estímulo da sensibilidade ao ser tocado pela estudante com baixa visão e facilitar sua visualização. A decisão pelo uso destes estímulos (cores fortes e texturas) foi tomada baseando-se na experiência cotidiana com a aluna e também pela pesquisa nos trabalhos selecionados e que compuseram o referencial teórico desta pesquisa. Apesar de não participar diretamente da confecção do material, a aluna com baixa visão contribuiu para que o modelo do sistema digestório permitisse a toda a turma uma gama de interações visuais e táteis.

Foi agendada uma aula para o dia 17/04/2019 de intervenção/complementação pedagógica do assunto que já havia sido ministrado em sala de aula pela professora responsável pelas determinadas aulas de ciências. O conteúdo sistema digestório humano havia sido ensinado aos alunos com as seguintes metodologias: explanação verbal, anotação em quadro negro e livro didático, porém insuficientes para a compreensão do conteúdo pelos alunos, em especial pela aluna com deficiência visual, fato este constatado a partir das respostas da primeira entrevista (Anexo I).

Em um primeiro momento da intervenção pedagógica, houve um rápido levantamento de conhecimentos prévios dos alunos sobre o assunto. Em seguida, as professoraspesquisadoras apresentaram aos alunos a maquete, retirando-se os órgãos um a um, explicando suas funções e localizações no corpo humano, repassando-os aos alunos para que melhor os 
visualizassem (Figura 3). Posteriormente, alguns alunos foram convidados a remontarem a maquete do sistema digestório humano e relembraram com seus colegas e as professoras as funções de todos esses órgãos.

Ao final da aula, cada aluno recebeu uma atividade impressa (Figura 4), que consistia em um esquema do sistema digestório humano, no qual os estudantes deveriam localizar e nomear todas as estruturas que compõem esse sistema. Esse exercício teve como objetivo avaliar a efetividade da intervenção pedagógica ministrada pelas professoras-pesquisadoras.

Devido ao planejamento desta intervenção pedagógica ser de apenas 50 minutos, as professoras-pesquisadoras não tiveram tempo suficiente para confeccionar a maquete em sala de aula juntamente com os alunos e ainda conseguir discutir o assunto Sistema Digestório Humano com eles, apresentando-os à maquete. Por esse motivo, a produção do material didático citado foi realizada apenas pelas professoras-pesquisadoras em um momento anterior à intervenção pedagógica proposta pelas mesmas. Além disso, o motivo da intervenção pedagógica ter sido realizada com toda a turma, e não apenas com a aluna com deficiência visual (que é o sujeito-foco do trabalho), teve como intuito trabalhar a participação coletiva e a inclusão, além de valores como respeito à diversidade e etc.

Após o encerramento da aula, foi aplicada somente para a aluna com baixa visão, reservadamente, uma segunda entrevista semiestruturada elaborada pelas autoras (Anexo 2). O intuito dessa segunda entrevista foi avaliar a percepção da aluna com baixa visão acerca da metodologia de trabalho utilizada na intervenção pedagógica pelas professoras-pesquisadoras, que abordou o sistema digestório utilizando como material adaptado uma maquete ilustrativa. Desta vez, as perguntas feitas à aluna foram: "Você já teve experiência como a de hoje, com a utilização de materiais palpáveis, semelhantes à matéria que estava sendo ensinada pela professora?", "A forma como as professoras explicaram o conteúdo de sistema digestório facilitou sua aprendizagem? Por quê?", "Você sentiu-se mais motivada e interessada pelo conteúdo que foi explicado pelas professoras com a utilização de um material palpável, semelhante ao sistema digestório? Justifique sua resposta", "Descreva o que você mais gostou de aprender nesta aula", "Comparando a aula que você teve hoje sobre sistema digestório, com as aulas que você costuma ter em Ciências e em outras matérias, em qual delas é mais fácil de aprender? Por quêe?" e "Se essa aula tivesse sido planejada de maneira apenas expositiva (explicações da professora) e utilizando o quadro, o giz e anotações no caderno, você teria tido mais motivação ou menos motivação para estudar o sistema digestório? Por 
quê??". As respostas da aluna podem ser conferidas no Anexo II e documentam uma prática pedagógica bem sucedida.

Amparadas nos referenciais teóricos selecionados, as professoras-pesquisadoras analisaram os dados coletados por meio de uma abordagem com paradigma qualitativo. Como técnica para a análise destes dados, além da observação das professoras durante a prática em sala de aula, utilizou-se a análise documental dos questionários aplicados à aluna com baixa visão.

\section{Resultados E Discussões}

Após realização da primeira entrevista semiestruturada (Anexo 1), observou-se que a aluna com baixa visão possuía certa preferência por aulas mais didáticas, dinâmicas e diversificadas, com utilização de recursos didáticos, visto que esse tipo de aula, segundo relato da própria aluna, facilitava sua visão e, consequentemente, a sua aprendizagem. Dessa forma, identificou-se que esses recursos didáticos mais interativos teriam o potencial para complementar a explicação que o professor de Ciências fez sobre um determinado conteúdo.

De acordo com Grosz e Almeida (2017), a forma habitual de metodologias de ensino, como aula expositiva com utilização de livros didáticos e anotações no quadro negro ainda está presente no cotidiano escolar de muitos professores e alunos da educação básica no Brasil. Essa forma de ensinar está limitada em apenas transferir, de forma mecanizada, os conhecimentos do professor aos alunos e os conteúdos encontrados nos livros didáticos. Por isso, é de suma importância reconhecer que o professor, como responsável pelo comando das aulas e transmissão do conhecimento científico, precisa procurar novas metodologias de ensino e recursos didáticos, com a finalidade de despertar o interesse e a participação dos alunos. Dessa maneira, os jogos lúdicos, as aulas com recursos didáticos, como, por exemplo, a utilização de materiais tridimensionais ou maquetes para explicar um conteúdo, aparecem como bons aliados, visto que são capazes de promover o ensino-aprendizagem de forma significativa, facilitando a compreensão, a contextualização e o aprendizado.

Conforme relatos de Souza (2007), a utilização de recursos didáticos no processo de ensino-aprendizagem é importante para que o aluno assimile o conteúdo trabalhado, desenvolvendo sua criatividade. Assim, ao ministrarmos o conteúdo do sistema digestório humano para os estudantes de uma turma de oitavo ano da educação básica da rede pública estadual de Minas Gerais, foi perceptível a dificuldade encontrada por esses estudantes na compreensão e assimilação dos órgãos que compõem esse sistema e suas respectivas funções, 
quando feito apenas com explicações e utilização do livro didático. Contudo, para a aluna com baixa visão, notou-se uma maior dificuldade, pois ela não compreendia muito bem as imagens do livro didático.

As respostas dadas pela aluna com baixa visão durante a primeira entrevista permitem a constatação relatada acima. Ao ser questionada sobre uma aula de Ciências que havia the marcado pela forma como o conteúdo foi trabalhado, a aluna respondeu: "Uma aula no ano passado, eu estava no sétimo ano, em que a professora deu sobre animais em slides com imagens". Pela leitura corporal e outros sinais durante a fala da aluna, as professoraspesquisadoras notaram que o uso de imagens ampliadas foi uma experiência positiva para a aluna.

Ao ser questionada sobre o que poderia ser melhorado nas aulas de Ciências para facilitar a sua aprendizagem, a aluna respondeu que: "Queria que a professora perguntasse se tenho dúvidas e trouxesse também 'aquele material [referindo-se aos slides] que tem imagens que é melhor para ver e outros materiais com cores fortes e grandes".

De acordo com estudos lidos, pode-se afirmar que os recursos didáticos nos quais os alunos conseguem observar imagens, representações animadas, sobre o que está sendo ministrado pelo professor são de grande relevância, visto que, dessa maneira, o professor consegue demonstrar melhor o conhecimento trabalhado e permite que o aluno consiga também, através dessa observação, uma melhor compreensão desse conteúdo. Neste contexto, Santos e Belmino (2013) destacam que os recursos didáticos são componentes do ambiente educacional capazes de estimular os educandos, facilitando e enriquecendo o processo de ensino e aprendizagem.

Após realização da primeira entrevista semiestruturada, foi organizada e ministrada uma aula em que foi explorado o tema sistema digestório humano (seus órgãos e glândulas anexas com suas respectivas funções no corpo humano). A professora responsável pela disciplina de Ciências dessa turma de oitavo ano, já havia trabalhado este conteúdo com os alunos de forma tradicional: anotação no quadro negro, explicação verbal e atividades do livro didático.

Pelo arcabouço social e profissional das professoras-pesquisadoras, entende-se que o ensino de ciências e biologia fundamentado apenas em aulas teóricas explicativas com atividades do livro didático e anotações no quadro negro, sem atividades práticas, com escassez de estratégias metodológicas e o elevado número de conceitos científicos, transformam a sala de aula em um lugar sem atrativos para os alunos, levando-os ao desinteresse, à desmotivação e ao desânimo pela disciplina. 
De acordo com Krasilchik (2005), os alunos apresentam dificuldade em imaginar uma estrutura tridimensional a partir de uma figura apresentada no plano do livro didático. Sendo assim os professores devem utilizar os modelos tridimensionais, como recursos didáticos em suas explicações, para facilitar aos alunos assimilarem o conteúdo. Valendo-se desse mesmo arcabouço e da primeira entrevista com a aluna, as professoras-pesquisadoras construíram um boneco de isopor simulando o sistema digestório humano com o intuito de permitir que os alunos visualizassem os seus órgãos e as glândulas auxiliares enquanto elas iam direcionando as explicações e abrindo espaço para o esclarecimento de dúvidas.

A Figura 1 registra o momento da construção do modelo pelas professoraspesquisadoras, que representa o sistema digestório que seria trabalhado em sala de aula no momento oportuno.

Figura 1 - Confecção do sistema digestório humano em um boneco de isopor pelas professoras-pesquisadoras.

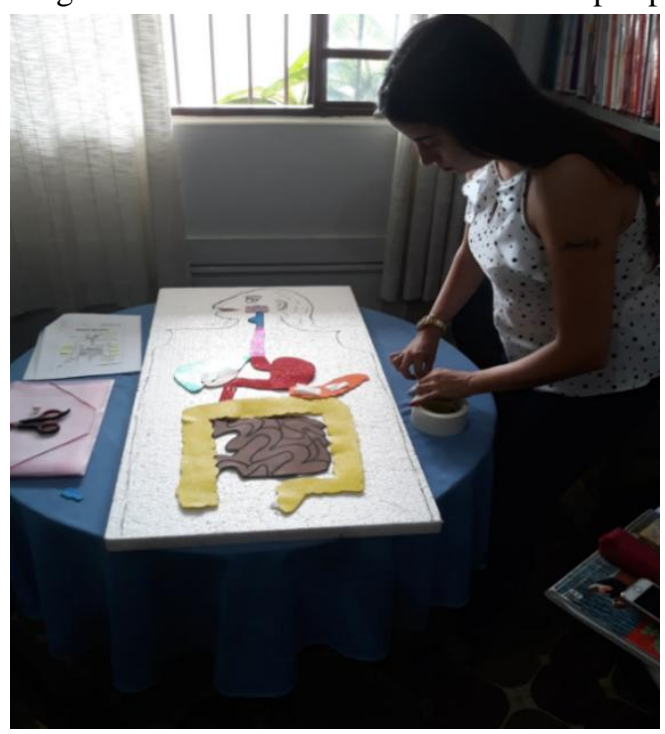

Fonte: autoria própria.

A Figura 2 mostra o sistema digestório humano pronto no boneco de isopor após ter sido confeccionado pelas professoras pesquisadoras. 
Figura 2 - Boneco de isopor confeccionado pelas professoras-pesquisadoras

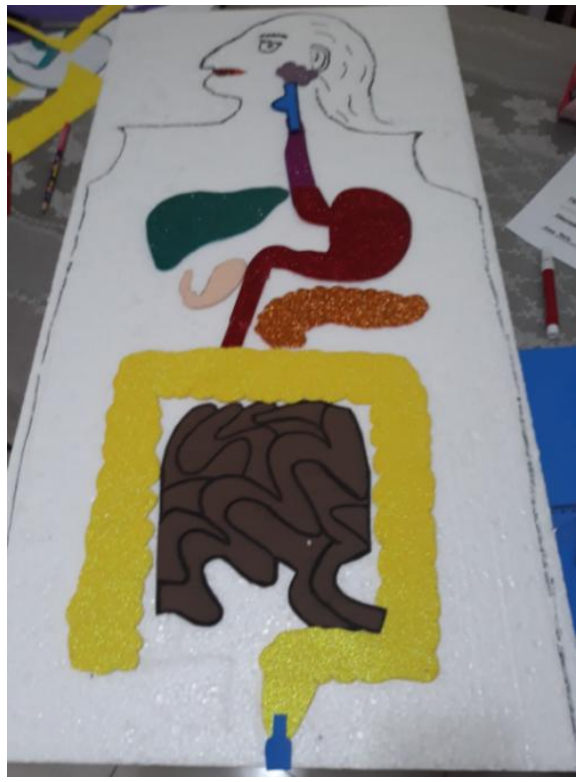

Fonte: autoria própria.

Os alunos, em especial a aluna com baixa visão, demonstraram muita empolgação na explicação do conteúdo com a observação do sistema digestório humano no boneco de isopor e com a liberdade para a manifestação livre das dúvidas e entendimentos. Esse momento da aula foi de grande valia, pois os alunos, além de verem o sistema digestório humano completo, ouviram a explicação das professoras-pesquisadoras sobre todos os órgãos do sistema digestório humano com suas respectivas funções, além de tocarem nas estruturas e sentirem seu formato.

Figura 3 - Explicação dos órgãos e glândulas anexas do sistema digestório pelas professoras-pesquisadoras; logo em seguida, estes foram repassados um a um aos alunos para que eles os apalpassem e sentissem o seu formato

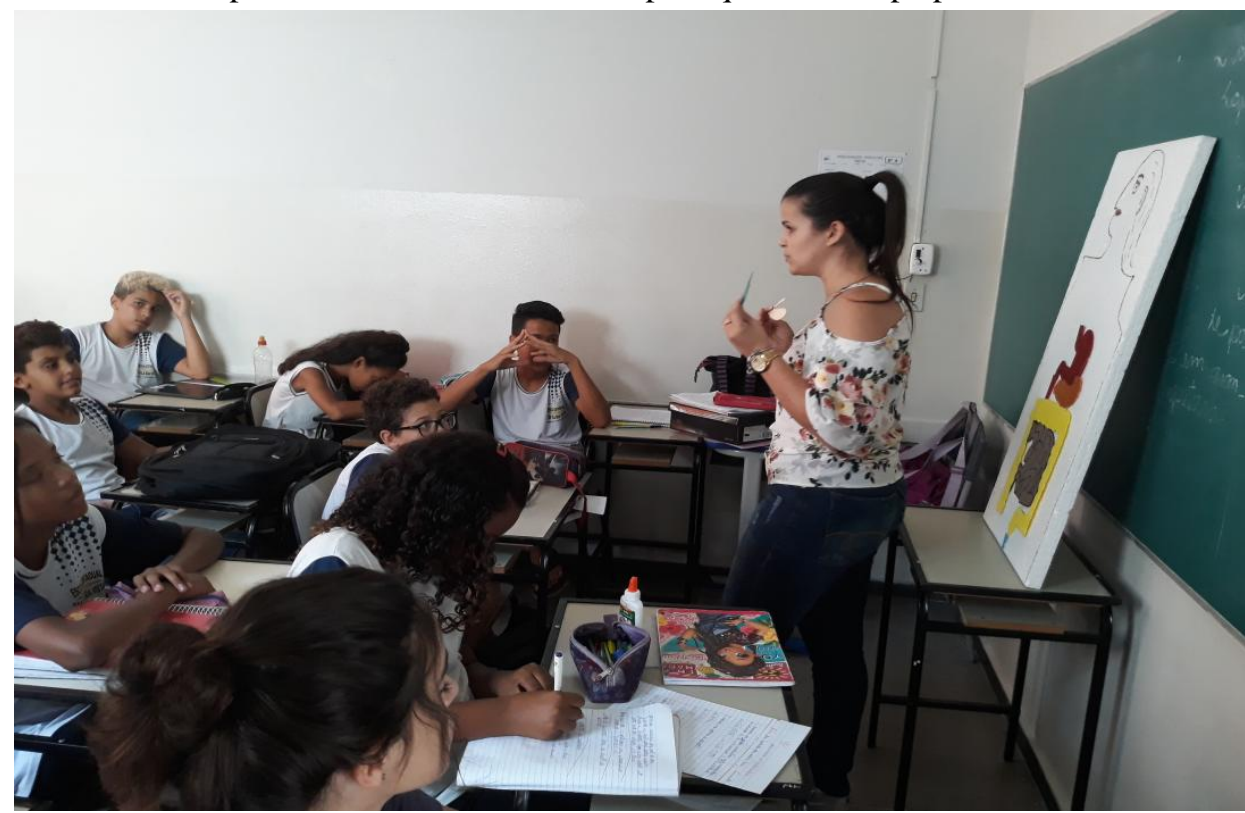

Fonte: autoria própria. 
Ao final da aula expositiva, foi entregue a todos os alunos uma atividade impressa sobre os órgãos do sistema digestório humano. Abaixo, segue a atividade realizada pela aluna com baixa visão.

Figura 4 - Atividade realizada pela aluna com baixa visão

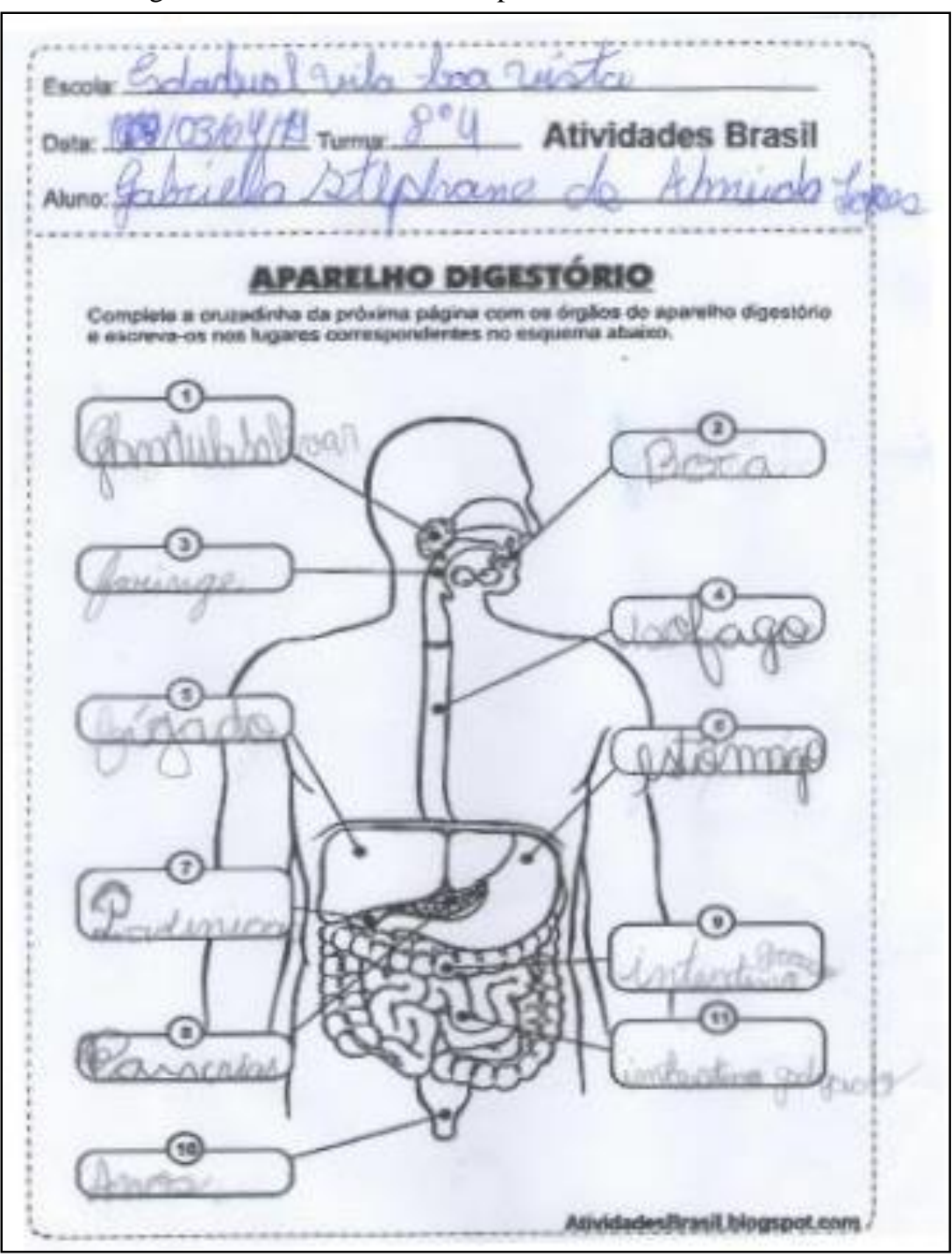

Fonte: autoria própria.

Com as respostas dadas pela aluna com baixa visão na atividade (Figura 4), percebeuse que ela não acertou apenas o nome e a localização dos órgãos e estruturas auxiliares, mas foi capaz de identificar, com clareza, a vesícula biliar (número 7), ou seja, foi capaz de gravar o nome e a localização de uma estrutura pequena e que se encontra localizada em área muito próxima ao fígado, habilidade conseguida com o uso importante do sentido do tato e de sua visão residual. Essa aluna teve um aproveitamento de mais de $90 \%$ de acertos na atividade proposta. 
A prática demonstrou os benefícios do uso do material didático adaptado e o sucesso da metodologia adotada pelas professoras-pesquisadoras na organização da aula sobre o sistema digestório humano: recurso didático lúdico em um esquema do sistema digestório humano em um boneco de isopor. Os resultados mostraram que os recursos didáticos são de extrema importância para o processo cognitivo da aluna com deficiência visual, pois promovem e facilitam o processo de ensino e aprendizagem e auxiliam no processo de inclusão dessa parcela de alunos em salas de ensino regular.

Ao analisarmos as respostas dadas pela aluna com baixa visão após a segunda entrevista, reforça-se o entendimento do quão positiva foi a prática em sala de aula. Ao ser questionada se a nova forma de organização da aula sobre o sistema digestório - com o uso do modelo representativo com órgãos em cores vivas e em alto relevo - havia facilitado o seu aprendizado, a aluna respondeu que : "ao pegar os órgãos e montar, consegui aprender direito a localização deles", atestando os benefícios da metodologia adotada para a organização da aula.

Questionada se ela se sentiu mais motivada e interessada pelo conteúdo trabalhado durante a aula foco do estudo, ela respondeu afirmativamente e justificou que "no livro não tem como pegar e nem montar os órgãos e, com o boneco de isopor, ficou melhor para ver as partes do sistema digestório e aprender sobre elas". Disse ainda que gostou de "aprender sobre os órgãos do sistema digestório; o fígado e a vesícula biliar foram os que mais gostei porque aprendi coisas que não sabia”, percepção que identifica uma aprendizagem significativa.

Buscando levar a aluna a refletir sobre as diferenças entre as duas aulas (expositiva e a prática com material didático adaptado), foi perguntado a ela de qual delas ela mais gostou e o porquê. "Mais fácil aprender foi usando o boneco, pois é melhor para guardar na memória, porque na hora da prova é mais fácil para lembrar; porque aprendi”, respondeu a aluna. Se a aula tivesse sido ministrada apenas de maneira expositiva, segundo o entendimento da própria aluna, ela teria tido "menos motivação, porque na aula com quadro e giz não consigo enxergar direito e isso me atrapalha a aprender".

Assim, ao acrescentarem a construção e inserção do modelo didático (ou modelo representativo) na metodologia de ensino em sala de aula, as professoras-pesquisadoras identificaram um efeito positivo coletivo, sendo evidenciado um maior interesse e participação dos estudantes, principalmente por parte da aluna com baixa visão. Consequentemente, essa mudança na organização da prática educativa facilitou a aprendizagem de toda a turma. 


\section{CONCLUSÃo}

Conforme apresentado no decorrer do texto, a Declaração Universal dos Direitos Humanos (ONU, 1948) assegura a todas as pessoas condições que lhes possibilitam viver com dignidade. Nesse contexto, a Constituição Federal Brasileira (BRASIL, 1988) surge para garantir os princípios de igualdade, o direito a uma educação de qualidade e destaca também importantes medidas constitucionais em prol das pessoas com necessidades especiais. A Constituição Brasileira determina também que o direito à educação deve ser de todos os cidadãos, além de igualdade e condições de acesso e permanência na escola, sendo dever do Estado assegurar o atendimento educacional especializado, preferencialmente na rede regular de ensino. Sendo assim, a Educação Especial deixou de ser vista como um sistema educacional paralelo ou segregado, adquirindo outro sentido conforme admite-se a educação como um direito de todos.

Com a universalização do ensino, as pessoas com necessidades educacionais especiais adquirem o direito de frequentarem a escola regular. A Lei de Diretrizes e Bases da Educação Nacional (LDB), n 9.394 (BRASIL, 1996), surgiu para garantir esse direito levando em conta que uma educação de qualidade deve considerar os aspectos de cada aluno. Desse modo, o professor deve ser capaz de transmitir o seu conhecimento de acordo com a realidade de todos os alunos, sejam eles deficientes ou não, visto que para uma educação inclusiva de qualidade, além de inserir os alunos com necessidades especiais na escola, é necessária a criação de diversas metodologias de ensino para facilitar esse processo.

Sendo assim, de acordo com os resultados obtidos com a aula teórica utilizando recurso didático adaptado e com as duas entrevistas semiestruturadas realizadas com a aluna com baixa visão, conclui-se que a utilização de recursos didáticos lúdicos táteis e visuais no estudo do sistema digestório humano mostrou-se eficiente para a promoção da aprendizagem real e significativa da turma como um todo e da aluna com deficiência visual, em especial.

De igual maneira, pode-se concluir que o uso exclusivo de metodologias tradicionais como a aula expositiva com quadro negro, giz e livro didático, sem o incremento de outros recursos didáticos inovadores, acaba por não despertar nos alunos a curiosidade e o interesse em estudar aquela disciplina e ainda dificulta a aprendizagem dos alunos com algum tipo de deficiência visual.

Desse modo, concluímos que recursos didáticos lúdicos no processo de ensinoaprendizagem podem permitir uma aprendizagem dos alunos de forma mais satisfatória, ou seja, com a finalidade de tornar os conteúdos apresentados pelo professor mais 
contextualizados, propiciando aos alunos a ampliação de conhecimentos já existentes ou a construção de novos, facilitando esse processo. Com a utilização de recursos didáticos diferentes é possível tornar as aulas mais dinâmicas e interessantes, possibilitando que os alunos compreendam melhor os conteúdos ministrados em sala de aula.

\section{REFERÊNCIAS}

ALLVES, Ranyelly Gomes; FERREIRA, Karina Renata Rodrigues Costa; FONSECA, Alaeson da Silva; SILVA, Juliclécia Kelly da; SILVA, Luzia Guacira dos Santos. Material didático para o ensino do sistema digestório a alunos na condição de deficiência: contribuição da educação especial na formação docente. In: $69^{a}$ REUNIÃO ANUAL DA SBPC, 16 a 22 jul. 2017, UFMG, Belo Horizonte. Educação/Tópicos Específicos de Educação. Belo Horizonte, 16 a 22 jul. 2017. Disponível em: http://www.sbpcnet.org.br/livro/69ra/resumos/resumos/2337_14148dcb57c7afd83ba2843426 e03e7ee.pdf Acesso em: 10 jun. 2019.

ANDRADE, Daniela Pimenta de; IACHEL, Gustavo. A elaboração de recursos didáticos para o ensino de Astronomia para deficientes visuais. XI ENCONTRO NACIONAL DE PESQUISA EM EDUCAÇÃO EM CIÊNCIAS - XI ENPEC, Florianópolis, 3 a 6 de jul. de 2017. Disponível em: http://www.abrapecnet.org.br/enpec/xi-enpec/anais/resumos/R02911.pdf. Acesso em: 18 jun. 2019.

BRASIL. Lei no 8.069, de 13 de julho de 1990. Dispõe sobre o Estatuto da Criança e do Adolescente e dá outras providências. Diário Oficial [da] República Federativa do Brasil, Brasília, DF, 16 jul. 1990. Disponível em: http://www.planalto.gov.br/ccivil_03/LEIS/L8069.htm\#art266. Acesso em: 25 mai. 2019.

BRASIL. Ministério da Educação. Lei n 9.394, de 20 de dezembro de 1996. Estabelece as diretrizes e bases da educação nacional. Disponível em:

http://portal.mec.gov.br/seed/arquivos/pdf/tvescola/leis/lein9394.pdf Acesso em: 25 mai. 2019.

BRASIL. Constituição da República Federativa do Brasil de 1988. Disponível em: http://www.planalto.gov.br/ccivil_03/constituicao/constituicao.htm Acesso em: 22 mai. 2019.

CARDINALI, Sandra Mara Mourão. O ensino e aprendizagem da célula em modelos táteis para alunos cegos em espaços de educação formal e não formal. 2008. 108 p. Dissertação (Mestrado em Ensino de Biologia) - Pontifícia Universidade Católica de Minas Gerais - PUC Minas, Belo Horizonte, 2008. Disponível em:

http://www.biblioteca.pucminas.br/teses/EnCiMat_CardinaliSM_1.pdf. Acesso em: 03 jul. 2019.

GERHARDT, Tatiana Engel; SILVEIRA, Denise Tolfo. Métodos de Pesquisa. 1. ed. Rio Grande do Sul: UFRGS, 2009.

GRÖSZ, Liandra Cristine Belló; ALMEIDA, Ronny Hudson Faria de. Ensinando genética de forma lúdica: utilização de um jogo de tabuleiro para alunos do terceiro ano do ensino médio. Revista Prática Docente, v. 2, p. 336-350, Instituto Federal de Mato Grosso jul/dez 2017. 
Disponível em: http://periodicos.cfs.ifmt.edu.br/periodicos/index.php/rpd/article/view/86/45. Acesso em: 13 ago. 2019.

KRASILCHIK, Myriam. Prática de ensino de Biologia. São Paulo: Editora da Universidade de São Paulo, 2005. Disponível em: https://pt.scribd.com/document/342843211/Pratica-deEnsino-de-Biologia-Myriam-Krasilchik-4-Ed. Acesso em: 20 jun. 2019.

LAGUNA, Jacqueline de Cássia. A utilização de diferentes recursos pedagógicos como auxílio na aprendizagem de alunos com deficiência visual. 2012. 35 p. Monografia de Especialização (Especialização em Educação: Métodos e Técnicas de Ensino) - Universidade Tecnológica Federal do Paraná - UTFPR, Medianeira, 2012. Disponível em: http://repositorio.roca.utfpr.edu.br/jspui/handle/1/4735 Acesso em: 28 mai. 2019.

LONGHI, Maria Luiza Gonçalves; SCHIMIN, Eliane Strack. Modelagem: Estratégia facilitadora para a aquisição de conceitos em reprodução e desenvolvimento embrionário. UNICENTRO. Guarapuava-PR. Disponível em: http://www.diaadiaeducacao.pr.gov.br/portals/pde/arquivos/1081-4.pdf Acesso em: 25 mai. 2019.

ORGANIZAÇÃO DAS NAÇÕES UNIDAS. Declaração Universal dos Direitos Humanos. Assembleia Geral das Nações Unidas em Paris. 10 dez. 1948. Disponível em: https://www.ohchr.org/EN/UDHR/Documents/UDHR_Translations/por.pdf Acesso em: 22 mai. 2019.

SOUZA, Perla Ferreira de; FARIA, Joana Cristina Neves de Menezes. A construção e avaliação de modelos didáticos para o ensino de ciências morfológicas - Uma proposta inclusiva e interativa. Enciclopédia Biosfera, Centro Científico Conhecer, Goiânia, vol.7, n.13; p. 1550-1561, nov. 2011. Disponível em:

http://www.conhecer.org.br/enciclop/2011b/ciencias\%20humanas/a\%20construcao.pdf.

Acesso em: 05 jun. 2019.

SOUZA, Salete Eduardo de. O uso de recursos didáticos no ensino escolar. In: I ENCONTRO DE PESQUISA EM EDUCAÇÃO, IV Jornada de Prática de Ensino, XIII Semana de Pedagogia da Universidade Estadual de Maringá, Maringá, 2007. Disponível em: http://www.dma.ufv.br/downloads/MAT\%20103/2015-II/slides/Rec\%20Didaticos\%20\%20MAT\%20103\%20-\%202015-II.pdf. Acesso em: 12 ago. 2019.

SANTOS, Ovídia Kaliandra Costa; BELMINO, José Franscico David Barbosa. Recursos didáticos: uma melhoria na qualidade da aprendizagem. In: FÓRUM INTERNACIONAL DE PEDAGOGIA, Vitória da Conquista, 2013. Disponível em:

http://editorarealize.com.br/revistas/fiped/trabalhos/Trabalho_Comunicacao_oral_idinscrito_ fde094c18ce8ce27adf61aedf31dd2d6.pdf Acesso em: 18 jun. 2019.

YIN, Robert K. Estudo de caso: planejamento e métodos. Tradução de Daniel Grassi - 2.ed. Porto Alegre: Bookman, 2001.

Recebido em: 22 de janeiro de 2020.

Aprovado em: 30 de março de 2020. 


\section{ANEXO 1 - ENTREVISTA SEMIESTRUTURADA APLICADA ANTES DA SEQUÊNCIA DIDÁTICA}

1) A forma como as aulas de Ciências é organizada pela professora tem contribuído para o seu aprendizado? Conte-nos como normalmente são organizadas as suas aulas de Ciências.

Resposta da aluna: Sim. Mas a professora passa a matéria no quadro e explica. A professora de apoio que me ajuda a entender o que está escrito e a copiar.

2) Conte-nos sobre uma aula de Ciências que lhe marcou pela forma como o conteúdo foi trabalhado.

Resposta da aluna: Uma aula no ano passado que eu estava no sétimo ano que a professora deu sobre animais em slides com imagens grandes.

3) Em qual disciplina você sente mais motivada a estudar? Por quê?

Resposta da aluna: Ciências, porque ajuda a entender química e, quando eu crescer, quero ser formada em Química. Ajuda também a entender sobre plantas que eu gosto.

4) Fale sobre o que poderia ser melhorado nas aulas de Ciências para facilitar a sua aprendizagem.

Resposta da aluna: Gostaria de mudar de lugar e me sentar na frente para enxergar melhor o quadro, mas sou grande, então não tem como. Queria que a professora perguntasse se tenho dúvidas e trouxesse também "aquele material" [referindo-se aos slides] que tem imagens, que é melhor para ver, e outros materiais com cores fortes e grandes. 


\section{ANEXO 2 - ENTREVISTA SEMIESTRUTURADA APLICADA DEPOIS DA SEQUÊNCIA DIDÁTICA}

1) Você já teve experiência como a de hoje, com a utilização de materiais palpáveis, semelhantes à matéria que estava sendo ensinada pela professora?

Resposta da aluna: Sim. Acho que no sexto ano em Ciências, a professora usou alguns materiais e em Geografia também já fizemos maquete.

2) A forma como as professoras explicaram o conteúdo de sistema digestório facilitou sua aprendizagem? Por quê?

Resposta da aluna: Sim. Porque ao pegar os órgãos e montar, consegui aprender direito a localização deles.

3) Você sentiu-se mais motivada e interessada pelo conteúdo que foi explicado pelas professoras com a utilização de um material palpável, semelhante ao sistema digestório? Justifique sua resposta.

Resposta da aluna: Sim, no livro não tem como pegar e nem montar os órgãos. Com o boneco de isopor ficou melhor para ver as partes do sistema digestório e aprender sobre elas.

4) Descreva o que você mais gostou de aprender nesta aula.

Resposta da aluna: Gostei de aprender sobre os órgãos do sistema digestório. O fígado e a vesícula biliar foram os que mais gostei porque aprendi coisas que não sabia.

5) Comparando a aula que você teve hoje sobre sistema digestório, com as aulas que você costuma ter em Ciências e em outras matérias, em qual delas é mais fácil de aprender? Por quê? Resposta da aluna: Mais fácil aprender foi usando o boneco, pois é melhor para guardar na memória, porque na hora da prova é mais fácil para lembrar; porque aprendi.

6) Se essa aula tivesse sido planejada de maneira apenas expositiva (explicações da professora) e utilizando o quadro, o giz e anotações no caderno, você teria tido mais motivação ou menos motivação para estudar o sistema digestório? Por quê?

Resposta da aluna: Menos motivação, porque na aula com quadro e giz não consigo enxergar direito e isso me atrapalha a aprender. 